Article

\title{
Fabrication of $\mathrm{Bi}_{2} \mathrm{WO}_{6}$ quantum dots/ultrathin nanosheets 0D/2D homojunctions with enhanced photocatalytic activity under visible light irradiation
}

\author{
Jingjing $\mathrm{Xu}^{\mathrm{a}}{ }^{\mathrm{a}}$, Junpeng Yue ${ }^{\mathrm{a}}$, Junfeng Niu ${ }^{\mathrm{b}}$, Mindong Chen a, Fei Teng ${ }^{\mathrm{a}}$ \\ a Jiangsu Key Laboratory of Atmospheric Environment Monitoring and Pollution Control, School of Environmental Science and Engineering, Collaborative \\ Innovation Center of Atmospheric Environment and Equipment Technology, Jiangsu Engineering Technology Research Center of Environmental Cleaning \\ Materials, Nanjing University of Information Science and Technology, Nanjing 210044, Jiangsu, China \\ ${ }^{\mathrm{b}}$ Research Center for Eco-Environmental Engineering, Dongguan University of Technology, Dongguan 523808, Guangdong, China
}

\section{A R T I C L E I N F O}

\section{Article history:}

Received 24 May 2018

Accepted 6 July 2018

Published 5 December 2018

\section{Keywords:}

$\mathrm{Bi}_{2} \mathrm{WO}_{6}$

Quantum dots

Nanosheet

Photocatalysis

Homojunction

\begin{abstract}
A B S T R A C T
A novel visible light-responsive homogeneous catalyst based on $\mathrm{Bi}_{2} \mathrm{WO}_{6}$ quantum dots (QDs-BWO) $/ \mathrm{Bi}_{2} \mathrm{WO}_{6}$ nanosheets (N-BWO) was successfully fabricated through a simple hydrothermal method. A variety of techniques were employed to investigate the morphology, structure, and electronic properties of the samples. The photocatalytic performance of the QDs/N-BWO materials was investigated by monitoring the degradation of 4-chlorophenol and rhodamine $\mathrm{B}$ under visible light irradiation. The as-fabricated QDs/N-BWO materials showed higher photocatalytic activity than both QDs-BWO and N-BWO. The results reveal that the incorporation of the QDs improved the separation efficiency of electron-hole pairs, leading to enhanced photocatalytic activity. Moreover, the results of quenching experiments show that $\cdot \mathrm{O}_{2}{ }^{-}$species played a major role in the degradation process. This work provides an important reference for the fabrication of homogeneous catalysts with high performance in the degradation of different types of pollutants.
\end{abstract}

(C) 2018, Dalian Institute of Chemical Physics, Chinese Academy of Sciences.

Published by Elsevier B.V. All rights reserved.

\section{Introduction}

With the rapid development of industrial activities, environmental pollution has become a global challenge. In order to solve these problems, there is a very urgent need for the development of renewable and environmentally friendly technologies for environmental pollution remediation [1-3]. Among various proposed technologies, semiconductor-based photocatalysis has attracted great attention worldwide [4-6], owing to its ability to directly utilize solar energy for the degradation of harmful pollutants and hydrogen production [7-10]. Titanium dioxide $\left(\mathrm{TiO}_{2}\right)$ is one of the most extensively studied photocatalyst systems. However, due to its large band gap (3.0-3.2 eV), $\mathrm{TiO}_{2}$ only absorbs in the ultraviolet region $(\sim 5 \%)$ and hardly responds to visible light $(\sim 45 \%)$ in the solar spectrum [11-14]. Therefore, the development of highly efficient photocatalysts that can utilize visible light is a crucial requirement.

In recent years, bismuth-based semiconductors have attracted widespread attention as typical visible light-responsive photocatalysts [15-20]. As a typical Aurivillius oxide, $\mathrm{Bi}_{2} \mathrm{WO}_{6}$ has excellent chemical stability, appropriate band gap, and high photoactivity. $\mathrm{Bi}_{2} \mathrm{WO}_{6}$ is composed of oxygen-sharing $\left[\mathrm{Bi}_{2} \mathrm{O}_{2}\right]^{2+}$ groups and perovskite-type layers. This special structure facili-

* Corresponding author. Tel/Fax: +86-25-58731090; E-mail: xujj@seu.edu.cn, xujj@nuist.edu.cn

This work was supported by the Priority Academic Program Development of Jiangsu Higher Education Institutions (PAPD).

DOI: 10.1016/S1872-2067(18)63140-7 | http://www.sciencedirect.com/science/journal/18722067 | Chin. J. Catal., Vol. 39 , No. 12, December 2018 
tates the rapid separation of photogenerated charges [21-25]. Therefore, $\mathrm{Bi}_{2} \mathrm{WO}_{6}$ is one of the promising semiconductor materials for enhancing the photocatalytic utilization of solar energy. However, the high recombination of photogenerated electron-hole pairs in pure $\mathrm{Bi}_{2} \mathrm{WO}_{6}$ limits its photocatalytic activity [26-28]. In previous reports, various methods have been proposed to enhance the photocatalytic performance of $\mathrm{Bi}_{2} \mathrm{WO}_{6}$, such as noble metal deposition [29], ion doping [30], and heterostructure assembly [31,32]. Furthermore, a few studies of $\mathrm{Bi}_{2} \mathrm{WO}_{6}$ (BWO) quantum dots (QDs-BWO) have been reported $[33,34]$. In fact, according to the equation giving the average diffusion time of photocarriers from the bulk to the surface ( $\tau=r^{2} / \pi^{2} D$ ), decreasing the grain size may greatly reduce the charge carrier recombination and increase the photocatalytic activity $[35,36]$. Nevertheless, pure QDs often aggregate during the photocatalytic process, which results in lower surface area and photocatalytic performance [37]. Therefore, to prevent aggregation, it is necessary to fix the quantum dots on a substrate with large surface area. Ultrathin two-dimensional (2D) $\mathrm{Bi}_{2} \mathrm{WO}_{6}$ nanosheets can also reduce the photogenerated electron-hole transport path [38-40], resulting in higher photoactivity. Moreover, zero-dimensional (0D)/2D interfaces can be constructed through self-modification of QDs [41,42]. Due to quantum confinement effects, the QDs-BWO have a wider band gap; as a result, they form a staggered energy level with N-BWO, which also facilitates the separation of photoelectrons and holes and further improves their performance [43-45]. Therefore, this special structural design is highly promising.

In this work, QDs-BWO and $\mathrm{Bi}_{2} \mathrm{WO}_{6}$ nanosheets ( $\mathrm{N}-\mathrm{BWO}$ ) were combined to form $0 \mathrm{D} / 2 \mathrm{D}$ homojunctions, and their morphology, phase structure, and electronic/optical properties were carefully characterized. The photocatalytic activity of the formed homojunctions was assessed by monitoring the degradation of 4-chlorophenol (4-CP) and rhodamine B ( $\mathrm{RhB})$ under visible light irradiation. The mechanism behind the enhancement of the photocatalytic and pollutant degradation activity is discussed in detail.

\section{Experimental}

\subsection{Sample preparation}

All raw materials were of analytical grade and used directly. In a typical synthesis of QDs-BWO, $4.4 \mathrm{mmol}$ of sodium oleate and $0.8 \mathrm{mmol}$ of bismuth nitrate $\left(\mathrm{Bi}\left(\mathrm{NO}_{3}\right)_{3} \cdot 5 \mathrm{H}_{2} \mathrm{O}\right)$ were dispersed in distilled water $(40 \mathrm{~mL})$ to form a milky suspension, which was stirred and ultrasonically dispersed to fully dissolve. Then, $40 \mathrm{~mL}$ of an aqueous solution of sodium tungstate $\left(\mathrm{Na}_{2} \mathrm{WO}_{4} \cdot 2 \mathrm{H}_{2} \mathrm{O}, 0.8 \mathrm{mmol}\right)$ was added to the above suspension. After stirring for $2 \mathrm{~h}$, the resulting suspension was loaded into a $100 \mathrm{~mL}$ Teflon-lined stainless steel autoclave before treatment at $200{ }^{\circ} \mathrm{C}$ for $18 \mathrm{~h}$. The autoclave was cooled naturally to room temperature, after which the products were collected by centrifugation and washed several times with $n$-hexane and isopropanol, followed by drying at $60^{\circ} \mathrm{C}$ in air [46].

In the synthesis of N-BWO, $2 \mathrm{mmol}$ of $\mathrm{Na}_{2} \mathrm{WO}_{4} \cdot 2 \mathrm{H}_{2} \mathrm{O}$ and 4 mmol of $\mathrm{Bi}\left(\mathrm{NO}_{3}\right)_{3} \cdot 5 \mathrm{H}_{2} \mathrm{O}$ were slowly added into a $160 \mathrm{~mL}$ aqueous solution under vigorous magnetic stirring. Then, 0.024 g potassium bromide $(\mathrm{KBr})$ was added to the above solution. After being stirred for $2 \mathrm{~h}$, the resulting suspension was placed in a $200 \mathrm{~mL}$ Teflon-lined stainless steel autoclave and treated at $150{ }^{\circ} \mathrm{C}$ for $24 \mathrm{~h}$. After the autoclave was cooled to room temperature, the products were collected by centrifugation and washed with deionized water. Finally, N-BWO were obtained by drying at $60^{\circ} \mathrm{C}$ in air.

The QDs/N-BWO materials were synthesized through a simple self-assembly method. In the synthesis, $0.01 \mathrm{~g}$ of QDs-BWO and $1 \mathrm{~g}$ of N-BWO were mixed in a beaker with 50 $\mathrm{mL}$ of ethanol and dried at $60{ }^{\circ} \mathrm{C}$ in air under magnetic stirring. The zeta potential values for QDs-BWO and N-BWO were -3.51 and 1.38, respectively, indicating that QDs-BWO and N-BWO can be combined through electrostatic self-assembly. The QDs-BWO contents incorporated in the QDs/N-BWO materials were $1 \mathrm{wt} \%, 3 \mathrm{wt} \%, 5 \mathrm{wt} \%$, and $8 \mathrm{wt} \%$.

\subsection{Characterization}

The phase of the prepared samples was characterized using an XRD-6100 X-ray diffractometer ( $\mathrm{Cu} K_{\alpha}$ source) in the range of $10^{\circ}-80^{\circ}$ with a scan rate of $7^{\circ} \mathrm{min}^{-1}$. Transmission electron microscopy (TEM, JEOL JEM-200cx) was used to inspect the morphology of the samples. UV-vis diffuse reflectance spectroscopy (DRS) measurements were performed with a UV-vis Shimadzu UV-2450 spectrophotometer between 200 and 800 nm, using $\mathrm{BaSO}_{4}$ as a background. Photoluminescence (PL) measurements were carried out using a fluorescence spectrophotometer (Agilent, USA) at room temperature. The photocurrents were measured on an electrochemical workstation (CHI 660D, Chenhua Instrument Company).

\subsection{Photoelectrochemical measurements}

Photoelectrochemical measurements were conducted in a conventional three-electrode cell. In the photocurrent measurements, a fluoride tin oxide (FTO) conductor glass decorated with the sample was used as the working electrode, whereas a $\mathrm{Pt}$ wire and $\mathrm{Ag} / \mathrm{AgCl}$ served as a counter and reference electrodes, respectively. A $0.5 \mathrm{~mol} \mathrm{~L}^{-1} \mathrm{Na}_{2} \mathrm{SO}_{4}$ solution was used as the supporting electrolyte. The photoresponses of the samples were tested under visible light. In addition, Mott-Schottky curves were measured in a $\mathrm{Na}_{2} \mathrm{SO}_{4}$ aqueous solution $(0.5 \mathrm{~mol}$ $\mathrm{L}^{-1}$ ) at a frequency of $1 \mathrm{kHz}$.

\subsection{Photocatalytic experiments}

The performance of the prepared samples was investigated by monitoring the degradation of 4-CP and $\mathrm{RhB}$ under visible light, using a $300 \mathrm{~W}$ xenon lamp (CEL-HXF300, Beijing AuLight). In this experiment, $50 \mathrm{mg}$ of the catalyst was mixed thoroughly with an $\mathrm{RhB}$ or $4-\mathrm{CP}$ solution $(50 \mathrm{~mL})$ in a $100 \mathrm{~mL}$ beaker and then placed in a quartz photochemical reactor. Before the photocatalytic reaction, the suspension was stirred in the dark for $0.5 \mathrm{~h}$ to reach the adsorption-desorption equilibrium between pollutants and photocatalyst. At fixed intervals, 3 
$\mathrm{mL}$ of the suspension was collected and centrifuged at 12000 rpm. The concentration of RhB was analyzed by measuring the absorbance at $554 \mathrm{~nm}$ with a UV-vis spectrophotometer (Shimadzu UV-6100). The concentration of 4-CP was measured by a high-performance liquid chromatograph (Waters) equipped with a C18 column. The mobile phase was a 0.6/0.4 (v/v) acetonitrile-water mixture. The flow rate of eluent was $1 \mathrm{~mL} \mathrm{~min}^{-1}$ and the detection wavelength was $277 \mathrm{~nm}$.

\section{Results and discussion}

\subsection{Characterization of the as-prepared samples}

The structure of the samples was investigated by X-ray diffraction. In Fig. 1, the diffraction peaks of BWO appeared at $28.3^{\circ}, 32.8^{\circ}, 47.1^{\circ}, 55.8^{\circ}, 58.5^{\circ}$, and $69.0^{\circ}$, corresponding to the (131), (002), (202), (133), (262), and (400) planes, respectively, of the orthorhombic $\mathrm{Bi}_{2} \mathrm{WO}_{6}$ phase (JCPDS No. 79-2381) [47]. No other possible impurities were detected. In addition, the QDs-BWO sample exhibited wider and lower peaks than the N-BWO one, due to its small size and low crystallinity [48].

The morphology and structure of the QDs/N-BWO materials (Fig. 2(a)-(c)) were characterized by TEM. Fig. 2(a) shows the TEM image of pure N-BWO, which consisted of homogeneously dispersed nanosheets with a smooth surface. Fig. 2(b) shows the TEM image of pure QDs-BWO, whose particle diameter was approximately $5 \mathrm{~nm}$. Moreover, Fig. 2(c) shows that large amounts of QDs-BWO were uniformly deposited on the surface of N-BWO. This is a strong evidence of the successful formation of the QDs/N-BWO 0D/2D homojunctions.

Fig. 3 shows the DRS spectra of QDs/N-BWO materials with different QD contents. As shown in the figure, the QDs/N-BWO materials showed enhanced light-harvesting capability compared with pure N-BWO. This enhanced absorption capacity is expected to lead to the formation of a higher number of electron-hole pairs [49]. This could exist structure of homojunctions, due to the band gap difference between the QDs-BWO and N-BWO materials [50]. To further explore the structure of the homojunctions, we measured the relative positions of the

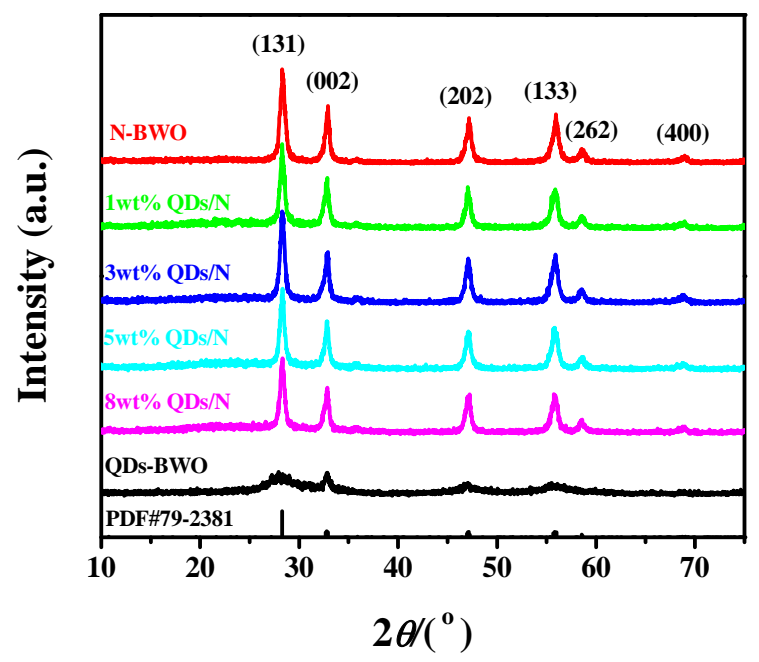

Fig. 1. XRD patterns of pure QDs-BWO and N-BWO.

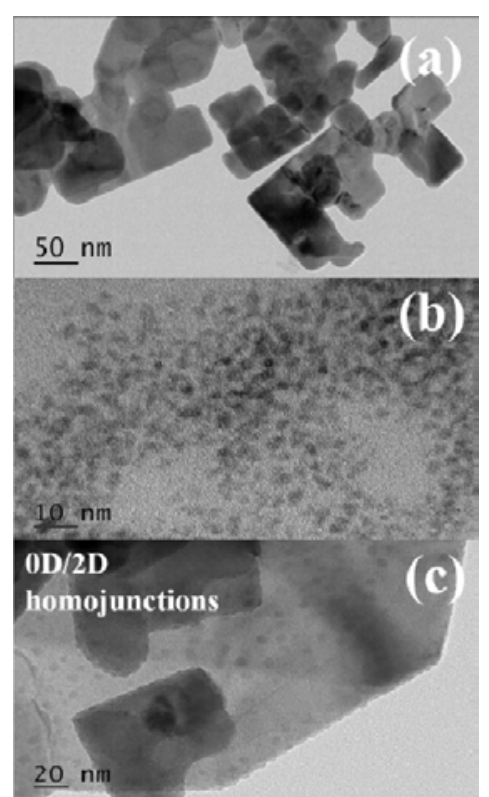

Fig. 2. TEM images of the as-prepared (a) N-BWO, (b) QDs-BWO, and (c QDs/N-BWO materials.

conduction band (CB) and valence band (VB) of pure QDs-BWO and N-BWO samples. Fig. 4(a) shows the $(\alpha h v)^{1 / 2}$ vs. $h v$ plots obtained according to the Kubelka-Munk method. Fig. 4(b) shows the Mott-Schottky plots of the QDs-BWO and N-BWO samples employed as electrodes [51,52]. Compared with pure N-BWO $(2.74 \mathrm{eV})$, the band gap of pure QD-BWO $(2.87 \mathrm{eV})$ showed a blue shift, caused by quantum confinement effects [53]. The flat-band potentials $\left(E_{\mathrm{fb}}\right)$ derived from Mott-Schottky plots were estimated to be $-0.86 \mathrm{eV}$ for QDs-BWO and $-0.52 \mathrm{eV}$ for $\mathrm{N}-\mathrm{BWO}$, using $\mathrm{Ag} / \mathrm{AgCl}$ as reference electrode. Therefore, the $\mathrm{CB}$ potentials of QDs-BWO and N-BWO were located at -0.66 and $-0.32 \mathrm{eV}$, respectively, with respect to the normal hydrogen electrode (NHE) [54,55]. The calculated position of the VB potential of $\mathrm{N}-\mathrm{BWO}(2.37 \mathrm{eV})$ is $0.16 \mathrm{eV}$ higher than that of QDs-BWO (2.21 eV), measured under the same experimental conditions. Due to the significantly different VB and CB posi-

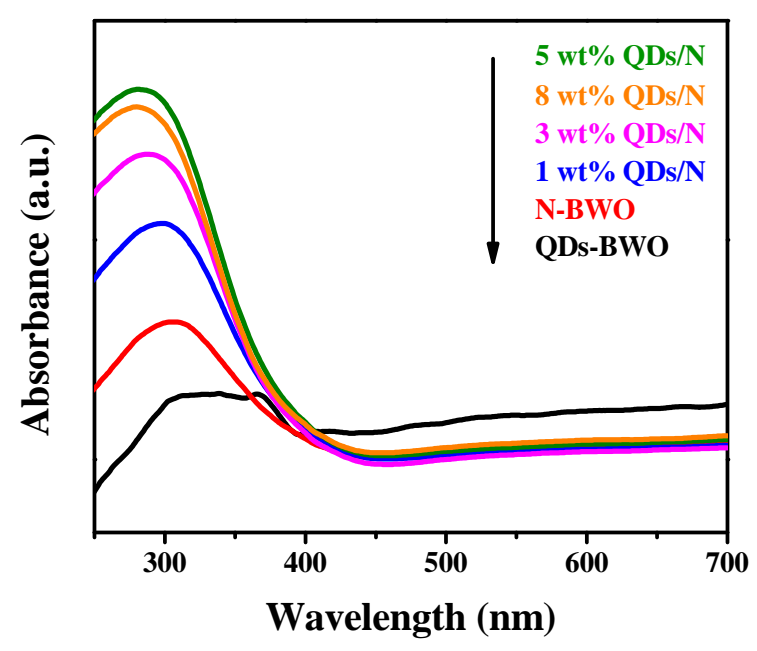

Fig. 3. UV-vis DRS curves of QDs/N-BWO materials. 

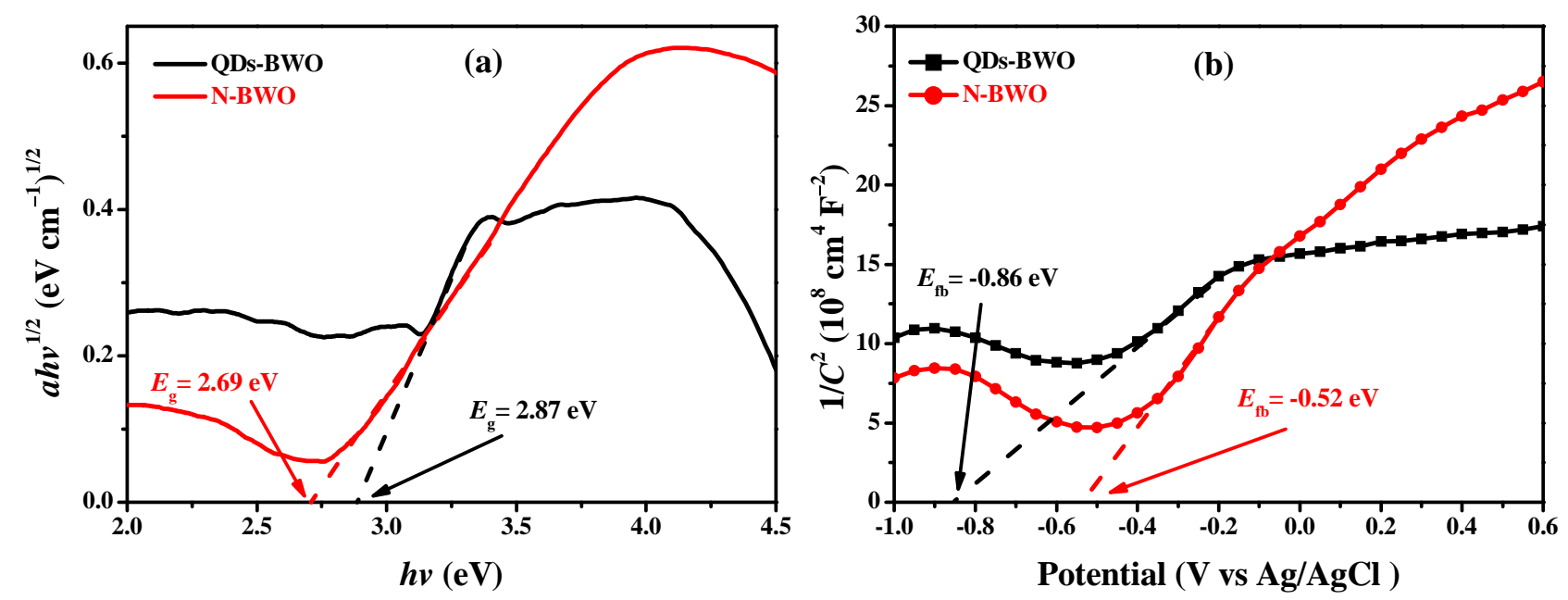

Fig. 4. (a) $(\alpha h v)^{1 / 2}$ vs. $h v$ plots of pure QDs-BWO and N-BWO samples; (b) Mott-Schottky plots of QDs-BWO and N-BWO electrodes.

tions of QDs-BWO and N-BWO, it can be predicted that the formed $0 \mathrm{D} / 2 \mathrm{D}$ homojunctions would help to reduce the recombination of photogenerated electron-hole pairs [56-58], thus resulting in a higher photocatalytic activity.

\subsection{Photocatalytic activity}

The photocatalytic activity of the different photocatalysts was assessed via the degradation of 4-CP and $\mathrm{RhB}$ under visible light irradiation. Before the photodegradation process, the catalyst and dyestuff were stirred in the dark for $30 \mathrm{~min}$ to achieve the adsorption-desorption equilibrium. The dynamic curves of $\mathrm{RhB}$ degradation in Fig. 5(a) show that all composite samples displayed higher photocatalytic degradation activity than the pure samples. This proves that the incorporation of quantum dots greatly enhances the photocatalytic activity of N-BWO. In particular, the sample modified with $5 \mathrm{wt} \%$ quantum dots exhibited the best photodegradation ability. The blank test shows that RhB cannot be degraded without the catalyst; therefore, the photolysis of $\mathrm{RhB}$ can be ignored. Moreover, we investigated the photocatalytic degradation kinetics of $\mathrm{RhB}$ under visible light irradiation. The plots of $\ln \left(C_{0} / C\right)$ vs. irradiation time are shown in Fig. 5(b), which shows that the RhB degradation curve follows a pseudo-first order kinetics $[59,60]$. The $5 \mathrm{wt} \%$ QDs/N-BWO material showed the highest degradation rate among all samples; the measured value $\left(0.32 \mathrm{~min}^{-1}\right)$ was about 6.4 and 2.1 times higher than those of QDs-BWO $\left(0.05 \mathrm{~min}^{-1}\right)$ and N-BWO $\left(0.15 \mathrm{~min}^{-1}\right)$, respectively.

4-CP is mainly used in pesticides, pharmaceuticals, dyes, and other industries, and may lead to various adverse effects on the water environment and humans even at low exposure levels. Fig. 6(a) shows the dynamic curves of 4-CP degradation under visible light irradiation. After $3.5 \mathrm{~h}$ of irradiation, the pure QDs-BWO and N-BWO materials degraded $38.1 \%$ and $61.2 \%$ of 4-CP, respectively. All composite samples degraded higher amounts of 4-CP than the pure samples. Among the different
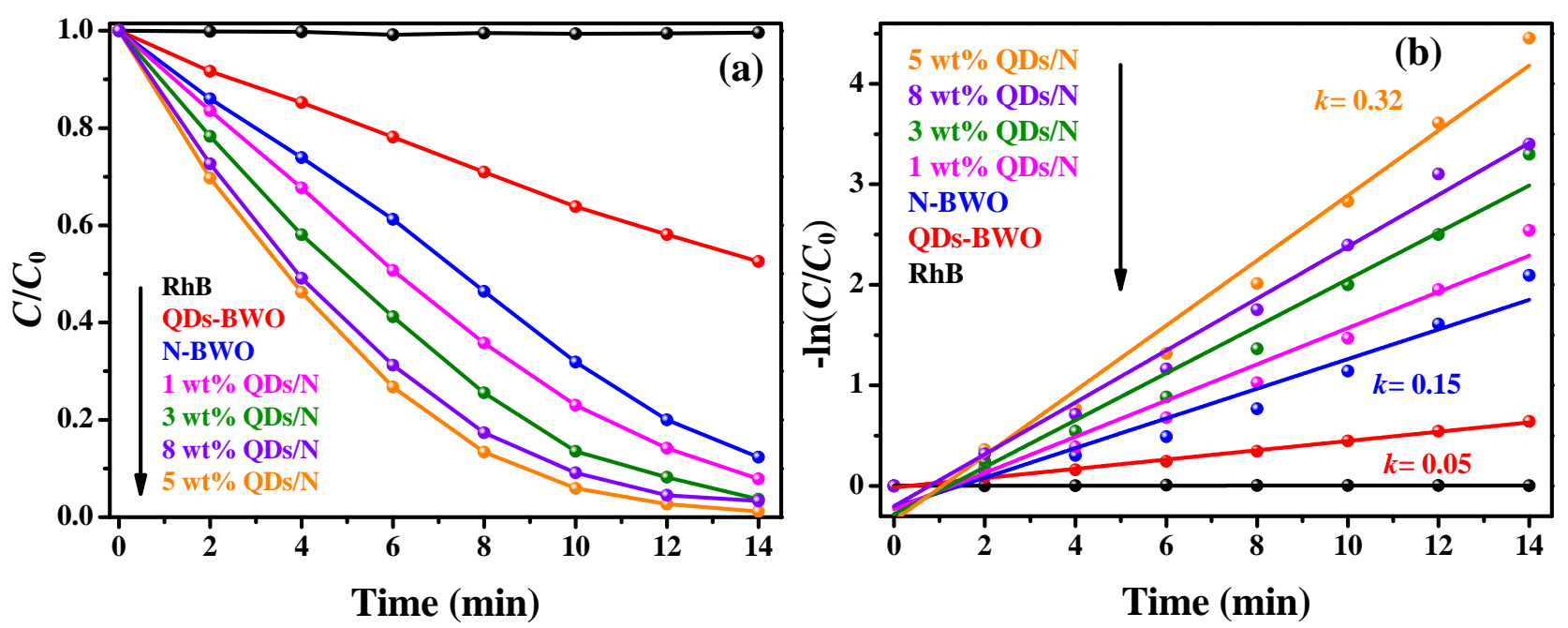

Fig. 5. (a) Dynamic curves of RhB photocatalytic degradation under visible light irradiation $(\lambda>400 \mathrm{~nm})$; (b) Plots of $\ln \left(C_{0} / C\right)$ vs. time. 


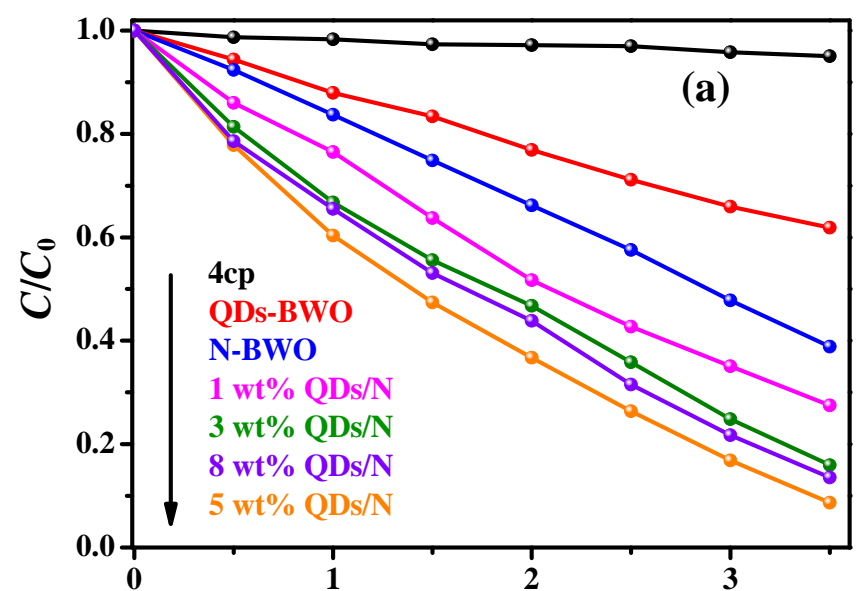

Time (h)

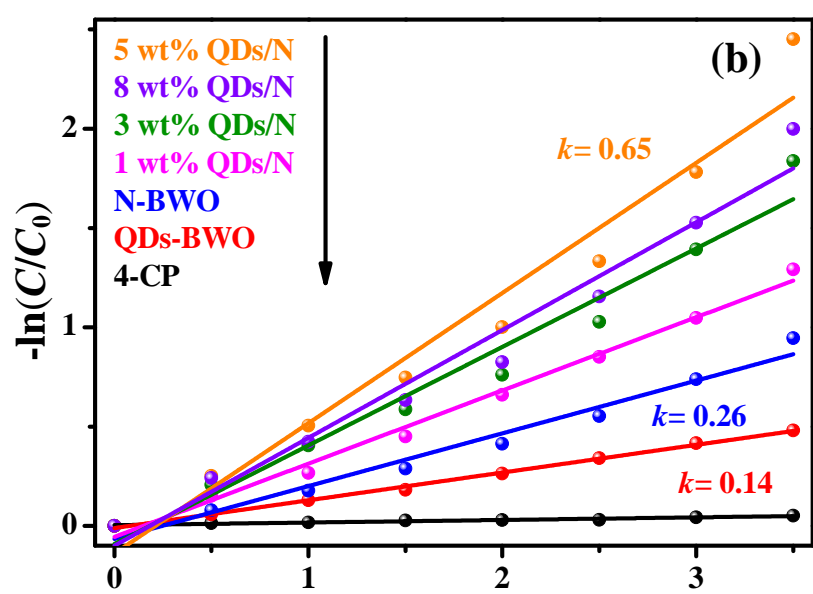

Time (h)

Fig. 6. (a) Dynamic curves of 4-CP photocatalytic degradation under visible light irradiation $(\lambda>400 \mathrm{~nm})$; (b) $\mathrm{Plots}$ of $\ln \left(C_{0} / C\right)$ vs. time.

composites, 5 wt $\%$ QDs/N-BWO had the highest photodegradation efficiency towards 4-CP, which reached about $86.5 \%$ after $3.5 \mathrm{~h}$ irradiation. As shown in Fig. 6(b), the 4-CP degradation curve also followed a pseudo-first order kinetics under visible light irradiation. The rate constant measured for $5 \mathrm{wt} \%$ QDs/N-BWO was 4.5 and 2.5 times higher than those of QDs-BWO and N-BWO, respectively.

We conducted cycling experiments of $\mathrm{RhB}$ degradation to evaluate the stability and reusability of the photocatalyst. No significant loss of photocatalytic activity of the sample was observed after four cycles (Fig. 7). This result indicates that the prepared sample possessed sufficient reusability and stability.

\subsection{Mechanism of photocatalytic activity and pollutant degradation enhancement}

$\mathrm{N}_{2}$ adsorption-desorption experiments (Fig. 8) were performed to determine the Brunauer-Emmett-Teller (BET) surface area of the samples. The obtained BET surface areas of

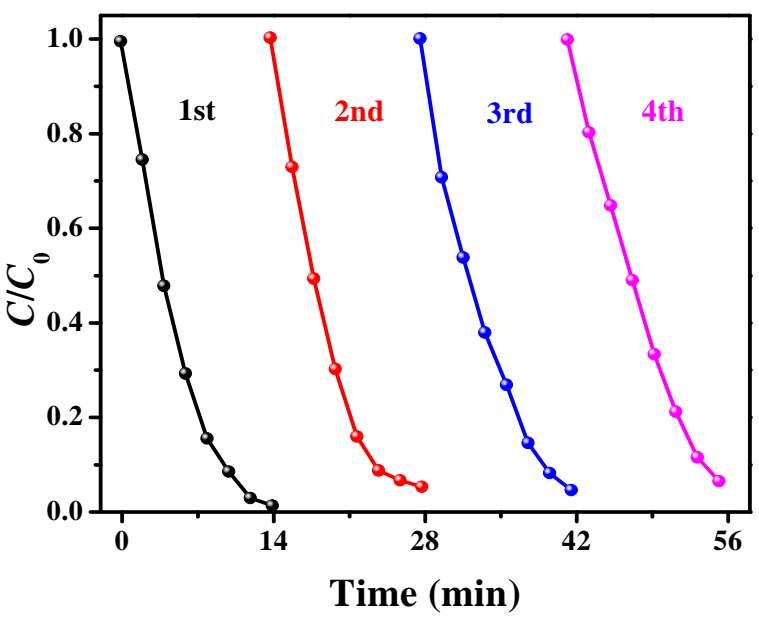

Fig. 7. Cycling tests of the photodegradation of RhB.
N-BWO and 5 wt\% QDs/N-BWO were 15.46 and $19.24 \mathrm{~m}^{2} \mathrm{~g}^{-1}$, respectively, showing that the BET surface area increased after deposition of QDs-BWO onto N-BWO. The increase in BET surface area results in the adsorption of higher numbers of pollutant molecules on the surface of the material, leading to the improved photocatalytic activity.

PL is a common method to explore the rate of recombination of charge carriers. Generally, the higher the PL intensity, the higher the recombination rate of photogenerated electron-hole pairs. Fig. 9 shows the PL spectra for pure QDs-BWO, pure N-BWO, and $5 \mathrm{wt} \%$ QDs/N-BWO materials. The figure shows that the PL emission intensity of the $5 \mathrm{wt} \%$ QDs/N-BWO material is lower than that of the QDs-BWO and N-BWO ones. This result indicates that the incorporation of QDs-BWO improved the separation efficiency of electron-hole pairs.

Electrochemical experiments were used to investigate the photogenerated carrier transfer and separation behavior of the present materials. Fig. 10 shows the photocurrent-time $(I-t)$

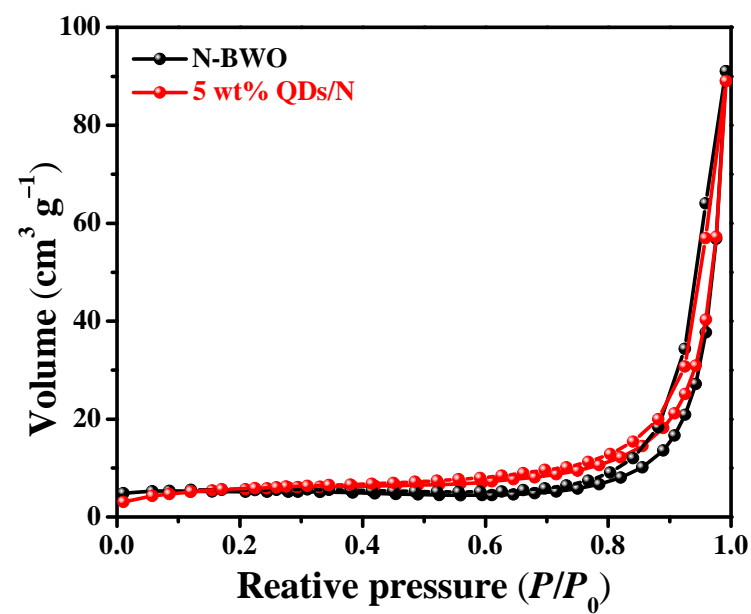

Fig. 8. Nitrogen adsorption-desorption isotherms of N-BWO and $5 \mathrm{wt} \%$ QDs/N-BWO samples. 


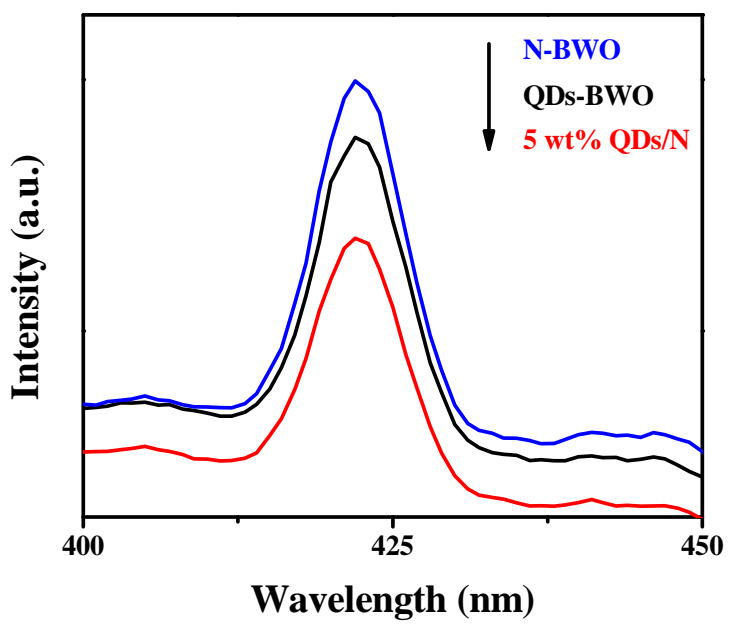

Fig. 9. Photoluminescence spectra of QDs-BWO, N-BWO, and $5 \mathrm{wt} \%$ QDs/N-BWO.

curves of pure N-BWO, QDs-BWO, and 5 wt\% QDs/N-BWO electrodes. Several intermittent on-off illumination cycles indicate that the sample photocurrent is stable and reproducible. Furthermore, the $5 \mathrm{wt} \%$ QDs/N-BWO exhibited a much higher photocurrent value than N-BWO and QDs-BWO, showing that the incorporation of QDs-BWO improves the transfer and separation efficiency of electron-hole pairs under visible light. This can be attributed to the staggered energy level formed between $\mathrm{N}$-BWO and QDs-BWO, which is beneficial for the transfer and separation of the photogenerated electron-hole pairs. This result also indirectly suggests a key role of the homojunction structure between QDs-BWO and N-BWO [61,62].

We used the electron spin resonance (ESR) technique to examine the active species produced by QDs-BWO, N-BWO, and $5 \mathrm{wt} \%$ QDs/N-BWO under visible light irradiation. It should be noted that no signal was detected for any of the samples in the dark. Fig. 11(a) shows the 5,5-dimethyl-1-pyrroline $\mathrm{N}$-oxide

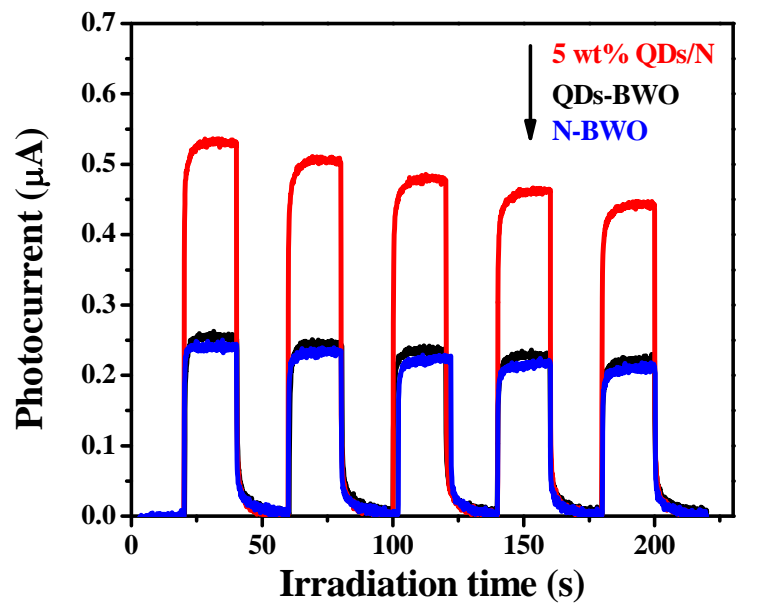

Fig. 10. Transient photocurrent responses of QDs-BWO, N-BWO, and 5 wt $\%$ QDs/N-BWO materials in $0.5 \mathrm{~mol} \mathrm{~L}^{-1} \mathrm{Na}_{2} \mathrm{SO}_{4}$ aqueous solution under visible light irradiation $(\lambda>400 \mathrm{~nm})$.

(DMPO)- $\bullet \mathrm{O}_{2}{ }^{-}$signals detected under visible light irradiation for 10 min. Six characteristic peaks (1:1:1:1) of DMPO- $\bullet \mathrm{O}_{2}{ }^{-}$can be distinctly observed for all samples, which indicates the formation of $\bullet \mathrm{O}_{2}{ }^{-}$radical species during the photocatalytic process. The figure also reveals that $5 \mathrm{wt} \%$ QDs/N-BWO exhibited the strongest $\mathrm{DMPO}-\bullet \mathrm{O}_{2}^{-}$signal, indicating that this material produced the highest amount of $\bullet_{2}{ }^{-}$species during the photocatalytic process. This result can be ascribed to the homojunctions formed between QDs-BWO and N-BWO, which help reducing the recombination of photogenerated electron-hole pairs; therefore, more electrons are captured to produce $\bullet_{2}{ }^{-}$ species. Fig. 11(b) shows that no DMPO-•OH signals were detected for QDs-BWO and N-BWO under visible light irradiation for $10 \mathrm{~min}$. This can be ascribed to the fact that the valence band potentials of QDs-BWO (2.21 eV vs. NHE) and N-BWO (2.37 eV vs. NHE) are not enough to oxidize water or surface hydroxyl groups (2.40 eV vs. NHE) and form $\bullet \mathrm{OH}$ species [63].
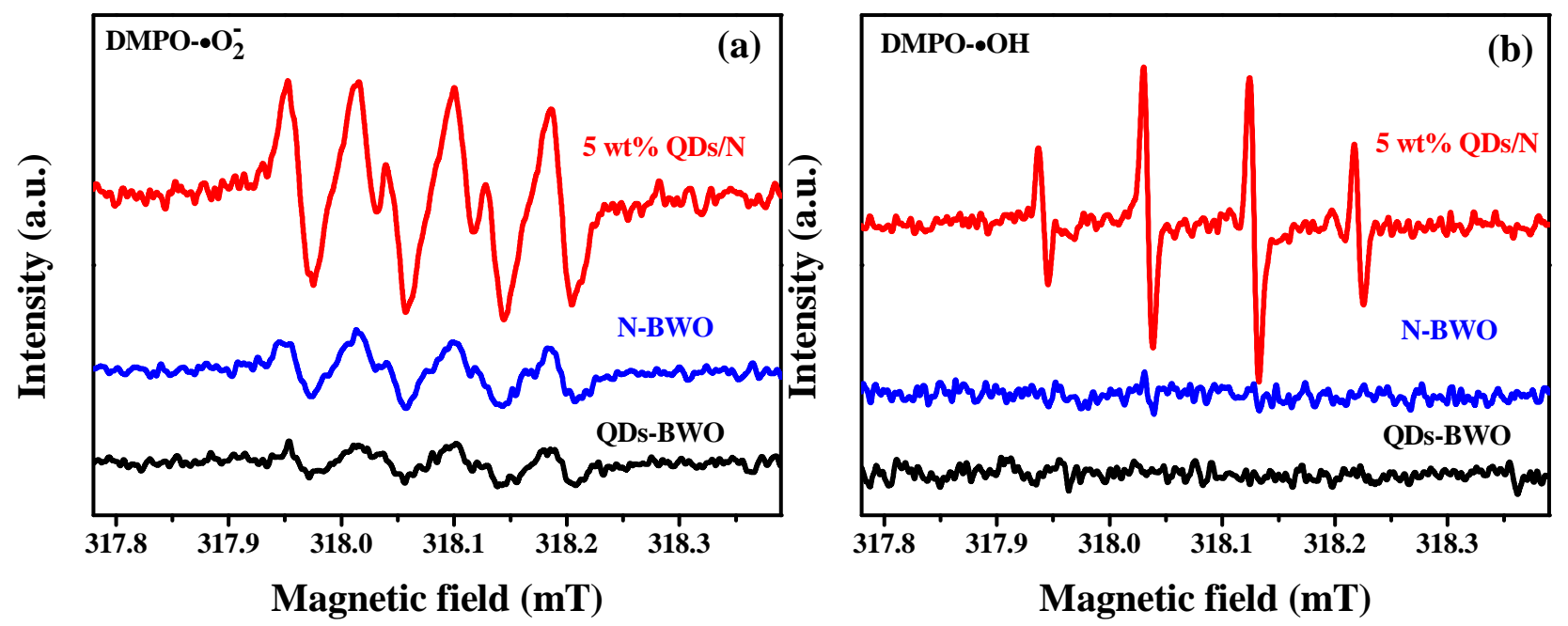

Fig. 11. ESR spectra of DMPO- $\bullet \mathrm{O}_{2}^{-}$(a) and DMPO-•OH (b) species generated by QDs-BWO, N-BWO, and 5 wt $\%$ QDs/N-BWO after 10 min of visible light irradiation. 


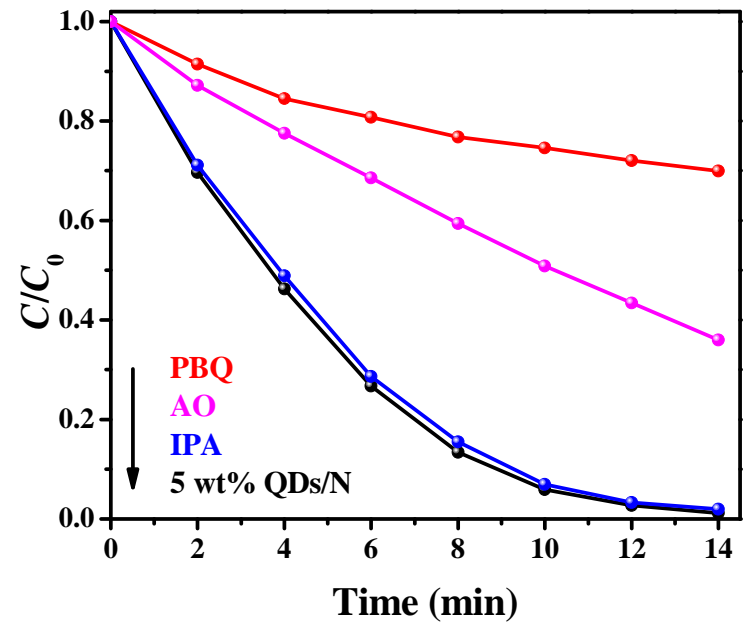

Fig. 12. Free radical trapping experiments under visible light irradiation.

However, we did observe the DMPO-•OH signals produced by QDs/N-BWO. We speculate that the DMPO-·OH signal generated by the QDs/N-BWO material can be attributed to the further reduction of $\bullet \mathrm{O}_{2}^{-}: \bullet \mathrm{O}_{2}^{-} \rightarrow \mathrm{H}_{2} \mathrm{O}_{2} \rightarrow \bullet \mathrm{OH}$.

In order to further investigate the active radicals present in the photocatalytic process, trapping experiments were carried out (Fig. 12). The addition of the $\bullet \mathrm{OH}$ scavenger isopropyl alcohol (IPA) did not affect the photocatalytic degradation of RhB by $5 \mathrm{wt} \%$ QDs/N-BWO. This indicates that the $\bullet \mathrm{OH}$ species has no effect in the photocatalytic reactions. However, the photodegradation process was substantially suppressed when $p$-benzoquinone (PBQ) was used as $\bullet \mathrm{O}_{2}{ }^{-}$scavenger. The addition of the $h^{+}$-scavenger ammonium oxalate (AO) suppressed the photocatalytic degradation of $\mathrm{RhB}$, indicating that the $h^{+}$ species also play a role in the photocatalytic degradation of $\mathrm{RhB}$ by the QDs/N-BWO. These results indicate that $\bullet_{2}{ }^{-}$and $h^{+}$ species act together in the photocatalytic degradation of $\mathrm{RhB}$, in which $\bullet \mathrm{O}_{2}{ }^{-}$plays a major role. These results are consistent with previous reports [64-66].

The photocatalytic mechanism of the QDs/N-BWO material is illustrated in Fig. 13. Under visible light irradiation, QDs-BWO and N-BWO are excited simultaneously and generate

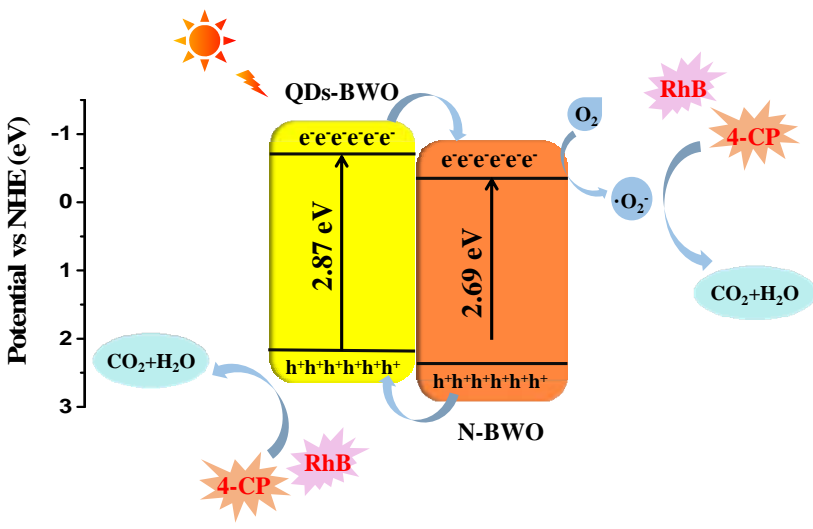

Fig. 13. Transfer and separation behavior of photogenerated charges and photocatalytic reaction mechanism in $5 \mathrm{wt} \%$ QDs/N-BWO. electron-hole pairs. In general, the generated electrons and holes recombine rapidly in the individual BWO material, limiting its photocatalytic activity. However, when QDs-BWO and $\mathrm{N}$-BWO assemble to form a homojunction, the electrons in the CB of QDs-BWO are easily transferred to the CB of N-BWO, because the $\mathrm{CB}$ of the former material is higher than that the latter. On the other hand, since the valence band of N-BWO is more positive than that of QDs-BWO, the photogenerated holes in N-BWO will flow to QDs-BWO. The difference in the energy band positions in the two materials promotes the separation of electron-hole pairs, thereby improving the photocatalytic activity. Finally, $\bullet \mathrm{O}_{2}{ }^{-}$and holes are generated to degrade organic contaminants.

\section{Conclusions}

We have successfully prepared composite photocatalysts based on QDs/N-BWO 0D/2D homojunctions. $\mathrm{Bi}_{2} \mathrm{WO}_{6}$ quantum dots were evenly dispersed on the surface of $\mathrm{Bi}_{2} \mathrm{WO}_{6}$ nanosheets. Compared with the pure $\mathrm{Bi}_{2} \mathrm{WO}_{6}$ nanosheets or quantum dots, the photocatalytic performance of the prepared QDs/N-BWO samples in the degradation of 4-CP or RhB under visible light irradiation was significantly improved. Among all prepared samples, the $5 \mathrm{wt} \%$ QDs/N-BWO material showed the best photocatalytic properties. The enhanced photocatalytic activity is ascribed to the homojunctions formed between QDs and nanosheets, which improve the separation efficiency of photoinduced electron-hole pairs.

\section{References}

[1] W. D. Zhang, Z. W. Zhao, F. Dong, Y. X. Zhang, Chin. J. Catal., 2017, $38,372-378$

[2] X. Z. Yuan, H. Wang, J. J. Wang, G. M. Zeng, X. H. Chen, Z. B. Wu, L. B. Jiang, T. Xiong, J. Zhang, H. Wang, Catal. Sci. Technol., 2018, 8, 1545-1554.

[3] W. D. Zhang, X. L. Liu, X. A. Dong, F. Dong, Y. X. Zhang, Chin. J. Catal,, 2017, 38, 2030-2038.

[4] Y. H. Ao, K. D. Wang, P. F. Wang, C. Wang, J. Hou, Appl. Catal. B, 2016,194, 157-168.

[5] P. Chen, F. Dong, M. X. Ran, J. R. Li, Chin. J. Catal., 2018, 38, 619-629

[6] M. H. Cao, P. F. Wang, Y. H. Ao, C. Wang, J. Hou, J. Qian, J. Colloid Interface Sci., 2016, 467, 129-139.

[7] L. B. Jiang, X. Z. Yuan, G. M. Zeng, Z. B. Wu, J. Liang, X. H. Chen, L. J. Leng, H. Wang, H. Wang, Appl. Catal. B, 2018, 221, 715-725.

[8] Y. Guo, P. F. Wang, J. Qian, Y. H. Ao, C. Wang, J. Hou, Appl. Catal. B, 2018, 234, 90-99.

[9] P. F. Wang, Y. Ao, C. Wang, J. Hou, J. Qian, Carbon, 2012, 50, 5256-5264.

[10] Y. J. Sun, X. Xiao, X. A. Dong, F. Dong, W. Zhang, Chin. J. Catal., 2017, $38,217-226$

[11] J. X. Low, B. Cheng, J. G. Yu, Appl. Surf. Sci., 2017, 392, 658-686.

[12] X. F. Wang, R. Yu, K. Wang, G. Q. Yang, H. G. Yu, Chin. J. Catal., 2015, $36,2211-1218$.

[13] N. Nie, L. Y. Zhang, J. W. Fu, B. Cheng, J. G. Yu, Appl. Surf. Sci., 2018, $441,12-22$.

[14] Y. G. Tan, Z. Shu, J. Zhou, T. T. Li, W. B. Wang, Z. L. Zhao, Appl. Catal. $B, 2018,230,260-268$. 


\section{Graphical Abstract}

Chin. J. Catal., 2018, 39: 1910-1918 doi: 10.1016/S1872-2067(18)63140-7

Fabrication of $\mathrm{Bi}_{2} \mathrm{WO}_{6}$ quantum dots/ultrathin nanosheets
OD/2D homojunctions with enhanced photocatalytic activity under visible light irradiation

Jingjing Xu*, Junpeng Yue, Junfeng Niu, Mindong Chen, Fei Teng Nanjing University of Information Sciences and Technology; Dongguan University of Technology

$\mathrm{Bi}_{2} \mathrm{WO}_{6}$ quantum dots and $\mathrm{Bi}_{2} \mathrm{WO}_{6}$ nanosheets form a unique zero-dimensional (0D)/two-dimensional (2D) homojunction. This structure promotes the transfer and separation of photogenerated electron-hole pairs, which greatly enhances the photocatalytic activity.

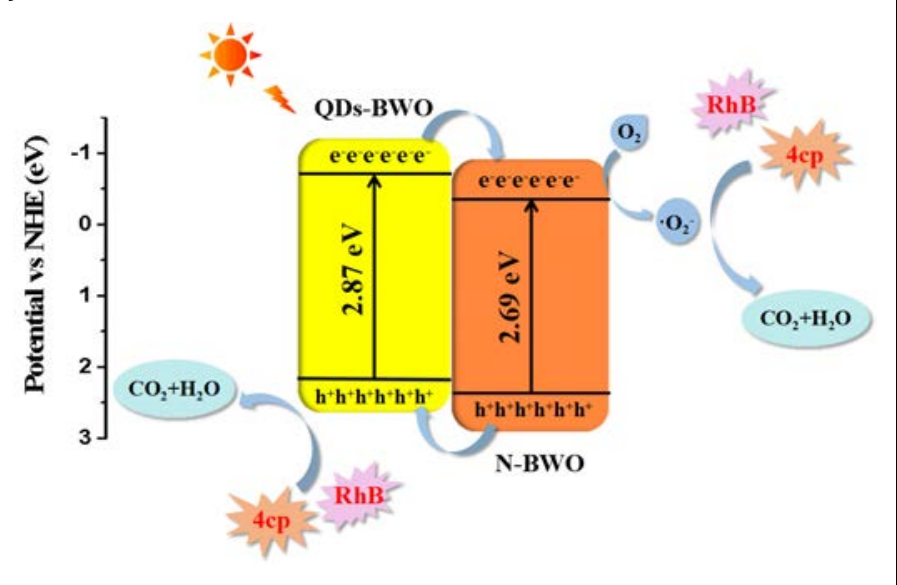

[15] X. F. Wang, D. Liao, H. G. Yu, J. G. Yu, Dalton Trans., 2018, 47, 6370-6377.

[16] L. S. Zhang, K. H. Wong, Z. G. Chen, J. C. Yu, J. C. Zhao, C. Hu, C. Y. Chan, P. K. Wong, Appl. Catal. A, 2009, 363, 221-229.

[17] H. G. Yu, C. Cao, X. F. Wang, J. G. Yu, J. Phys. Chem. C., 2017, 121, 13191-13201.

[18] D. Ma, J. Wu, M. C. Gao, Y. J. Xin, T. J. Ma, Y. Y. Sun, Chem. Eng. J., 2016, 290, 136-146.

[19] L. S. Zhang, H. L. Wang, Z. G. Chen, P. K. Wong, J. S. Liu, Appl. Catal. $B, \mathbf{2 0 1 1}, 106,1-13$.

[20] J. X. Xia, J. Di, S. Yin, H. Xu, J. Zhang, Y. G. Xu, L. Xu, H. M. Li, M. X. Ji, RSC Adv., 2014, 4, 82-90.

[21] Y. L. Tian, B. B. Chang, J. L. Lu, J. Fu, F. N. Xi, X. P. Dong, ACS Appl. Mater. Interfaces, 2013, 5, 7079-7085.

[22] C. Y. Wang, H. Zhang, F. Li, L. Y. Zhu, Environ. Sci. Technol, 2010, 44, 6843-6848.

[23] J. J. Xu, Y. H. Ao, M. D. Chen, Mater. Lett., 2013, 92, 126-128.

[24] X. Chu, G. Shan, C. Chang, Y. Fu, L. Yue, L. Zhu, Front. Environ. Sci. Eng., 2016, 10, 211-218.

[25] P. Xu, G. M. Zeng, D. L. Huang, C. L. Feng, S. Hu, M. H. Zhao, C. Lai, Z. Wei, C. Huang, G. X. Xie, Sci. Total Environ., 2012, 424, 1-10.

[26] M. Shang, W. Z. Wang, L. Zhang, S. M. Sun, L. Wang, L. Zhou, J. Phys. Chem. C, 2009, 113, 14727-14731.

[27] S. Obregón, G. Colón, Appl. Catal. B, 2013, 140-141, 299-305.

[28] J. Zhang, L. H. Huang, H. Y. Jin, Y. L. Sun, X. M. Ma, E. P. Zhang, H. B. Wang, Z. Kong, J. H. Xi, Z. G. Ji, Mater. Res. Bull., 2017, 85, 140-146.

[29] J. Meng, X. Q. Xiong, X. Zhang, Y. M. Xu, Appl. Surf. Sci., 2018, 439, 859-867.

[30] G. Q. Tan, J. Huang, L. L. Zhang, H. J. Ren, A. Xia, Ceram. Int., 2014, 40, 11671-11679.

[31] Z. F. Du, C. Cheng, L. Tan, J. W. Lan, S. X. Jiang, L. D. Zhao, R. H. Guo, Appl. Surf. Sci., 2018, 435, 626-634.

[32] S. Jonjana, A. Phuruangrat, S. Thongtem, T. Thongtem, Mater. Lett., 2018, 216, 92-96.

[33] J. Q. Li, N. Lei, L. Guo, Q. Q. Song, Z. Liang, ChemElectroChem, 2018, 5, 300-308.

[34] Z. Y. Jiang, X. Z. Liang, H. L. Zheng, Y. Y. Liu, Z. Y. Wang, P. Wang, X. Y. Zhang, X. Y. Qin, Y. Dai, M. H. Whangbo, B. B. Huang, Appl. Catal. $B, \mathbf{2 0 1 7}, 219,209-215$.

[35] A. Hagfeldt, M. Gratzel, Chem. Rev., 1995, 95, 49-68.

[36] T. L. Thompson, J. T. Yates Jr, Chem, Rev., 2006, 106, 4428-4453.
[37] S. M. Sun, W. Z. Wang, L. Zhang, J. Phys. Chem. C, 2013, 117, 9113-9120.

[38] Y. G. Zhou, Y. F. Zhang, M. S. Lin, J. L. Long, Z. Z. Zhang, H. X. Lin, J. C. S. Wu, X. X. Wang, Nat. Commun., 2015, 6, 8340.

[39] L. Pan, J. J. Zou, S. B. Wang, Z. F. Huang, A. Yu, L. Wang, X. W. Zhang, Chem. Commun., 2013, 49, 6593-6595.

[40] J. Li, G. M. Zhan, Y. Yu, L. Z. Zhang, Nat. Commun., 2016, 7, 11480.

[41] Y. F. Sun, S. Gao, F. C. Lei, C. Xiao, Y. Xie, Acc. Chem. Res., 2015, 48, 3-12.

[42] Y. F. Sun, Z. H. Sun, S. Gao, H. Cheng, Q. H. Liu, J. Y. Piao, T. Yao, C. Z. Wu, S. L. Hu, S. Q. Wei, Y. Xie, Nat. Commun., 2012, 3, 1057.

[43] J. J. Wang, L. Tang, G. G. Zeng, Y. C. Deng, H. R. Dong, Y. N. Liu, L. L. Wang, B. Peng, C. Zhang, F. Chen, Appl. Catal. B, 2018, 222, 115-123.

[44] Y. H. Peng, Q. H. Liu, J. Q. Zhang, Y. Zhang, M. J. Geng, J. Q. Yu, J. Phys. Chem. C, 2018, 122, 3738-3747.

[45] K. Wang, G. K. Zhang, J. Li, Y. Li, X. Y. Wu, ACS Appl. Mater. Interfaces, 2017, 9, 43704-43715.

[46] W. Chen, T. Y. Liu, T. Huang, X. H. Liu, J. W. Zhu, G. R. Duan, X. J. Yang, Appl. Surf. Sci., 2015, 355, 379-387.

[47] Z. K. Cui, D. W. Zeng, T. T. Tang, J. Liu, C. S. Xie, Catal. Commun., 2010, 11, 1054-1057.

[48] R. D. Robinson, B. Sadtler, D. O. Demchenko, C. K. Erdonmez, L. W. Wang, A. P. Alivisatos, Science, 2007, 317, 355-358.

[49] W. W. Liu, Y. Y. Shang, A. Q. Zhu, P. F. Tan, Y. Liu, L. L. Qiao, D. W. Chu, X. Xiong J. Pan, J. Mater. Chem. A, 2017, 24, 12542-12549.

[50] A. Kudo, I. Tsuji, H. Kato, Chem. Commun., 2002, 1958-1959.

[51] A. P. Zhang, J. Z. Zhang, Chin. J. Chem. Phys., 2010, 23, 73-78.

[52] H. W. Huang, R. R. Cao, S. X. Yu, K. Xu, W. C. Hao, Y. G. Wang, F. Dong, T. R. Zhang, Y. H. Zhang, Appl. Catal. B, 2017, 219, 526-537.

[53] S. M. Sun, W. Z. Wang, D. Jiang, L. Zhang, X. M. Li, Y. L. Zheng, Q. An, Nano Res., 2014, 7, 1497-1506.

[54] W. Chen, Y. X. Hua, Y. Wang, T. Huang, T. Y. Liu, X. H. Liu, J. Catal., 2017, 349, 8-18.

[55] M. L. Guan, C. Xiao, J. Zhang, S. J. Fan, R. An, Q. M. Cheng, J. F. Xie, M. Zhou, B. J. Ye, Y. Xie, J. Am. Chem. Soc., 2013, 135, 10411-10417.

[56] J. Di, J. X. Xia, Y. P. Ge, H. P. Li, H. Y. Ji, H. Xu, Q. Zhang, H. M. Li, M. N. Li, Appl. Catal. B, 2015, 168-169, 51-61.

[57] X. M. Zhang, B. Wang, Z. Q. Liu, J. Colloid Interfaces Sci., 2016, 484, 213-219.

[58] Y. Li, X. H. Feng, Z. X. Lu, H. Yin, F. Liu, Q. J. Xiang, J. Colloid Interfac- 
es Sci., 2018, 513, 866-876.

[59] I. K. Konstantinou, T. A. Albanis, Appl. Catal. B, 2014, 49, 1-14.

[60] L. W. Zhang, Y. Man, Y. F. Zhu, ACS Catal., 2011, 1, 841-848.

[61] L. M. Sun, Y. Qi, C. J. Jia, Z. Jin, W. L. Fan, Nanoscale, 2014, 6, 2649-2659.

[62] F. Dong, T. Xiong, S. Yan, H. Q. Wan, Y. J. Sun, Y. X. Zhang, H. W. Huang, Z. B. Wu, J. Catal., 2016, 344, 401-410.

[63] X. Ding, K. Zhao, L. Z. Zhang, Environ. Sci. Technol., 2014, 48,
5823-5831.

[64] H. B. Fu, S. C. Zhang, T. G. Xu, Y. F. Zhu, J. M. Chen, Environ. Sci. Technol., 2008, 42, 2085-2091.

[65] P. Chen, L. Y. Zhu, S. H. Fang, C. Y. Wang, G. Q. Shan, Environ. Sci. Technol., 2012, 46, 2345-2351.

[66] J. X. Low, J. G. Yu, Q. Li, B. Cheng, Phys. Chem. Chem. Phys., 2014, 16, 1111-1120.

\title{
可见光照射下具有增强光催化活性的 $\mathrm{Bi}_{2} \mathrm{WO}_{6}$ 量子点-超薄纳米片(0D/2D) 同质结结构
}

\author{
徐晶晶 ${ }^{\mathrm{a},}{ }^{*}$, 岳俊鹏 ${ }^{\mathrm{a}}$, 牛军峰 ${ }^{\mathrm{b}}$, 陈敏东 ${ }^{\mathrm{a}}$, 滕 飞 ${ }^{\mathrm{a}}$ \\ a南京信息工程大学环境科学与工程学院, 江苏省大气环境监测与污染控制高技术研究重点实验室, \\ 大气环境与装备技术协同创新中心，江苏省环境净化材料工程技术研究中心，江苏南京210044 \\ b东莞理工学院生态环境工程技术研发中心, 广东东莞523808
}

\begin{abstract}
摘要: 随着工业的快速发展, 环境污染问题成为全球性的挑战. 为了解决这些问题, 迫切需要开发用于环境污染治理的环 保、可再生技术. 在各种提出的技术中, 基于半导体的光催化引起广泛关注.

我们在前期研究中通过简单的水热法成功制备了新型可见光响应 $\mathrm{Bi}_{2} \mathrm{WO}_{6}$ 量子点(QDs-BWO)/ $\mathrm{Bi}_{2} \mathrm{WO}_{6}$ 纳米片(N-BWO) 同质结催化剂, 并以可见光照射下4-氯苯酚(4-CP)和罗丹明B (RhB)的降解实验研究了 QDs/N-BWO材料的光催化性能. 结 果表明, 相比纯QDs-BWO和纯N-BWO, 我们制备的QDs/N-BWO同质结材料具有更高的光催化活性. 然而, QDs/N-BWO 催化剂光催化性能提高的原因尚不清楚. 本文在上述研究的基础上, 采用透射电子显微镜(TEM)、 $\mathrm{N}_{2}$ 吸附-脱附实验、电子 自旋共振(ESR)、荧光分光光度计(PL)和电化学实验等表征手段研究了 QDs/N-BWO同质结催化剂光催化性能提高的原因.

TEM测试结果表明, 大量的QDs-BWO均匀附着在N-BWO表面, 意味着成功形成了 $0 \mathrm{D} / 2 \mathrm{D}$ 同质结结构. 同质结结构可 促进电子-空穴对的分离, 提高光催化性能. $\mathrm{N}_{2}$ 吸附-脱附实验结果表明, 在将QDs-BWO沉积到N-BWO上之后, BET比表面 积增加. BET表面积的增加有利于更多污染物分子在材料表面上吸附, 从而改善了光催化活性. 此外, ESR测试结果表明, 相同条件下, QDs/BWO同质结催化剂产生了更多的超氧自由基 $\left(\cdot \mathrm{O}_{2}{ }^{-}\right)$和羟基自由基 $(\cdot \mathrm{OH})$, 这也表明QDs-BWO和N-BWO 之间形成的同质结有助于减少光生电子-空穴对的复合. 荧光分光光度计和电化学实验的测试结果也充分验证了这一点. 另外, 为了研究光催化过程中的主要活性自由基, 我们进行了捕获实验. 结果表明, 超氧自由基和空穴在RhB光催化降解 中起主要作用, 这与之前报道的结果一致.

总之, 我们成功制备了 QDs/N-BWO (0D/2D)同质结光催化剂. QDs/N-BWO同质结光催化剂的光催化性能在可见光照 射下显著提高. 量子点和纳米片之间形成的同质结显著提高了电子-空穴对的分离效率, 提高了光催化性能.
\end{abstract}

关键词: 铇酸铋; 量子点; 纳米片; 光催化; 同质结

收稿日期: 2018-05-24. 接受日期: 2018-07-06. 出版日期: 2018-12-05.

*通讯联系人. 电话/传真: (025)58731090; 电子信箱: xujj@seu.edu.cn, xujj@nuist.edu.cn

基金来源：江苏高校优势学科建设工程(PAPD).

本文的电子版全文由Elsevier出版社在ScienceDirect上出版(http://www.sciencedirect.com/science/journal/18722067). 